\title{
QUESTÕES EMERGENTES SOBRE A INTERPRETAÇÃO DE LIBRAS- PORTUGUÊS NA ESFERA JURÍDICA
}

\author{
EMERGING ISSUES ON THE INTERPRETATION OF LIBRAS - PORTUGUESE \\ WITHIN THE LEGAL AREA
}

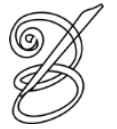 \\ Silvana Aguiar dos SANTOS ${ }^{\mathrm{i}}$ \\ Doutora em Estudos da Tradução (UFSC) \\ Professora Adjunta do Bacharelado em Letras/LIBRAS \\ Universidade Federal de Santa Catarina (UFSC) \\ Florianópolis, Santa Catarina, Brasil \\ aguiar.sil@gmail.com
}

Resumo: Neste artigo, proponho-me apresentar e discutir algumas dificuldades recorrentes enfrentadas pelos intérpretes de Libras-Português na esfera jurídica. Este trabalho caracteriza-se por uma abordagem qualitativa e de cunho descritivo. Como instrumento, aplicou-se um questionário (on-line) para intérpretes de LibrasPortuguês de diferentes regiões brasileiras nos meses de julho a agosto do ano de 2014. Os resultados obtidos apontaram que: (i) as formas de encaminhamento dos intérpretes de Libras-Português até o Judiciário são diversificadas, sendo muitas delas entrelaçadas pelas relações de amizade; (ii) há um desconhecimento do papel do intérprete de Libras-Português na esfera jurídica, dificultando a atuação deste profissional e, por fim, (iii) dificuldades com a terminologia específica da área jurídica. Diante dessas dificuldades, resgato contribuições teóricas de Russel (2002) que considera vários elementos relevantes para o desempenho dos intérpretes que atuam nesse meio. A partir desses resultados, compreende-se melhor o contexto de atuação dos intérpretes de Libras-Português na esfera jurídica. Além disso, corrobora-se a urgente necessidade de desenhos curriculares de formação específica por áreas para intérpretes de Libras-Português, dado que o escopo de atuação desse profissional é cada vez mais amplo.

Palavras-chave: Estudos da Interpretação. Intérpretes de Libras-Português. Esfera jurídica. Dificuldades.

Abstract: In this article, I propose to present and discuss some recurring difficulties faced by Portuguese Libras interpreters within the legal area. This work is characterized by a qualitative approach of a descriptive nature. As a survey instrument, we applied an online questionnaire to Libras - Portuguese interpreters from different Brazilian regions, during a period of time from July to August, 2014. The achieved results showed that: (i) Libras - Portuguese interpreters reach the judiciary through different ways, some of them, by means of friendship relations; (ii) there is a lack of understanding of the role of Libras - Portuguese interpreters within the legal area, hindering their work performance and, finally, (iii) there are difficulties regarding the specific terminology of the legal field. Considering such difficulties, I rely on the theoretical contributions of Russell (2002), who points to several relevant elements of interpreter's performance in this environment. Based on these results, the working context of Libras - Portuguese interpreters within the legal area is better understood. Moreover, they confirm the urgent need to design specific curricula for the area of Libras - Portuguese, since the professional scope of this field is becoming wider.

Keywords: Interpretation Studies. Libras - Portuguese interpreters. Legal area. Difficulties. 


\section{Introdução}

o Brasil, a atuação do intérprete de Libras-Português na esfera jurídica tornou-se $\mathrm{N}$ cada vez mais visível em nossa sociedade nos últimos anos, pois as pessoas surdas têm buscado exercer seus direitos enquanto cidadãos. Dessa forma, os intérpretes estão diante de diversos espaços de atuação na esfera jurídica. Mesmo antes do processo judicial em si, podem ser convocados para interpretar outras situações: instrução para investigação, tomada de depoimento em delegacia, assessoria jurídica e outros.

Em cada uma dessas etapas, o intérprete tem uma série de demandas com as quais precisa lidar durante o processo de interpretação. Algumas dessas demandas podem ser de ordem linguística (diferentes níveis de registro linguístico, termos específicos da área jurídica e outros) ou de ordem tradutória (melhor modo de interpretação — se simultâneo ou consecutivo-, modos de preparação da interpretação, estratégias como explicitação, adaptação, tradução literal, dentre outras, adotadas no processo de interpretação) ou, ainda, questões de ordem operacional (como proceder diante de uma convocação, qual posicionamento adotar no lugar reservado a este profissional - se próximo ao juiz, delegado 118 ou advogado), dentre outras.

Essas decisões podem ser tomadas de forma satisfatória se o intérprete tiver o máximo de informações sobre como proceder nesses casos, quais protocolos são indicados e quais não devem ser adotados, levando em consideração diversas circunstâncias, sejam elas de cunho linguístico, tradutório, operacional ou ainda cultural. Do contrário, isto é, pelo desconhecimento de algumas informações desse meio, os intérpretes de Libras-Português podem tomar decisões equivocadas em diferentes espaços de atuação da esfera jurídica. Considerando a realidade dos intérpretes de Libras-Português, o acesso a essas informações ainda é restrito, pois as orientações ou diretrizes de atuação profissional nesse meio circulam com pouca frequência em nosso país.

Uma das razões que podem dificultar esse acesso refere-se à falta de investimento governamental na profissionalização (cursos de formação, aquisição da literatura básica da área, desenvolvimento de pesquisas e outros) de intérpretes de Libras-Português que atuam no meio jurídico. Por exemplo, clássicos da área de interpretação na esfera jurídica como Edwards (1995), Russel (2002), Mathers (2006) e González et al. (2012) raramente circulam em nosso cotidiano acadêmico ou profissional.

Na década de noventa, Edwards (1995) contextualizava o trabalho e os princípios básicos de como tornar-se um intérprete no contexto jurídico, assim como, o papel, os 
procedimentos, a ética, a tradução de documentos legais, a previsão de erros dentre outras questões. Esses tópicos abordados por Edwards (1995) são mencionados com certa frequência no discurso de intérpretes de Libras-Português que desconhecem seu papel ou sequer possuem noção do que encontrarão à frente de uma interpretação no contexto legal.

O tema ainda é incipiente no país, carecendo de noções, orientações e diretrizes fundamentais na atuação do profissional nesse espaço. Quais etapas constituem um julgamento, quem participa dele, como o intérprete deve portar-se nesse contexto? Nessa perspectiva, Russel (2002) apresenta um panorama sobre a atuação do intérprete de língua de sinais na esfera jurídica, oferecendo um leque de possibilidades de como lidar e interagir com os participantes que constituem o contexto legal. A autora constata, a partir de simulações de julgamentos e de entrevistas pós-julgamentos (com advogados, juízes, testemunhas surdas, intérpretes e peritos), elementos que podem qualificar a prestação do serviço de intérpretes de Língua de Sinais Americana-Inglês em tribunais.

Esse conjunto de elementos tratados por Russel (2002) é pertinente para delinear o papel e a função do intérprete nesse meio. Nesse sentido, Mathers (2006) apresenta as melhores práticas que podem ser adotadas pelos intérpretes na esfera jurídica: na interpretação consecutiva durante depoimento, na tomada de notas da interpretação consecutiva durante testemunho, na interpretação simultânea, nas equipes de trabalho, no treinamento/experiência e certificação de intérpretes jurídicos, dentre outras. Portanto, no âmbito internacional há pesquisadores que investigaram a temática e não só ofereceram elementos que podem ser adotados na formação desses profissionais, como também, estabeleceram os fundamentos da atuação nesse meio.

O livro Fundamentals of Court Interpretation: Theory, Policy and Practice, de González et al. (2012), publicado pela primeira vez no ano de 1991, foi um dos primeiros da década de noventa a explorar os pilares (teoria, política e prática) como elementos centrais dos fundamentos da interpretação no contexto jurídico. Os autores discutem sobre as políticas linguísticas adotadas no contexto americano, os obstáculos enfrentados no acesso aos direitos linguísticos, a interpretação como uma profissão, os tipos de interpretação no contexto jurídico, dentre outras temáticas.

Em comum, todos esses autores colaboraram diretamente na profissionalização do intérprete que atua na esfera jurídica, pois a busca pela padronização da atuação profissional e a descrição das melhores práticas de atuação nesse meio elevaram a qualificação do trabalho desses profissionais. Esta contextualização inicial de algumas obras clássicas da interpretação 
na esfera jurídica corrobora a existência de uma área já consolidada no âmbito internacional dentro dos Estudos da Interpretação, qual seja, Interpretação legal e jurídica de acordo com o mapa apresentado pela editora St. Jerome Publishing. Diante desse cenário, inúmeras são as possibilidades de articulação e reflexões para a atuação de intérpretes de Libras-Português na esfera jurídica.

Dessa forma, a necessidade de conhecermos melhor o que se produz no cenário brasileiro referente à interpretação de Libras-Português nesse meio é iminente. A realidade estrangeira apontada nessas obras ainda é um pouco distante do contexto brasileiro, pois raras são as discussões, pesquisas e reflexões acerca da atuação do intérprete de Libras-Português na esfera jurídica em nosso país. Assim, o objetivo central deste artigo é compreender melhor as dificuldades e os desafios enfrentados pelos intérpretes de Libras-Português, a partir de uma pesquisa com abordagem qualitativa e de cunho descritivo. Como instrumento, aplicouse um questionário on-line para intérpretes de Libras-Português de diferentes regiões brasileiras nos meses de julho a agosto do ano de 2014.

$\mathrm{Na}$ próxima seção são apresentados alguns marcos históricos na interpretação de

120 Libras-Português na esfera jurídica. Em um segundo momento discutimos os procedimentos metodológicos da pesquisa e os resultados obtidos. Por fim, sugerem-se nas considerações finais algumas recomendações que levem em conta a formação específica desses profissionais.

\section{Alguns marcos históricos}

A atuação dos intérpretes de Libras-Português na esfera jurídica não é recente, mas os registros são bastante raros, dificultando a precisão de datas. Como mostra a figura abaixo, retirada do CD que acompanha a obra O INES e a educação de surdos no Brasil: aspectos da trajetória do Instituto Nacional de Educação de Surdos em seu percurso de 150 anos, publicada no ano de 2008, uma das primeiras solicitações de intérprete na esfera jurídica ocorreu no ano de 1907. 
Figura 1 - Registro de uma das primeiras solicitações de intérprete de Libras-Português na esfera jurídica

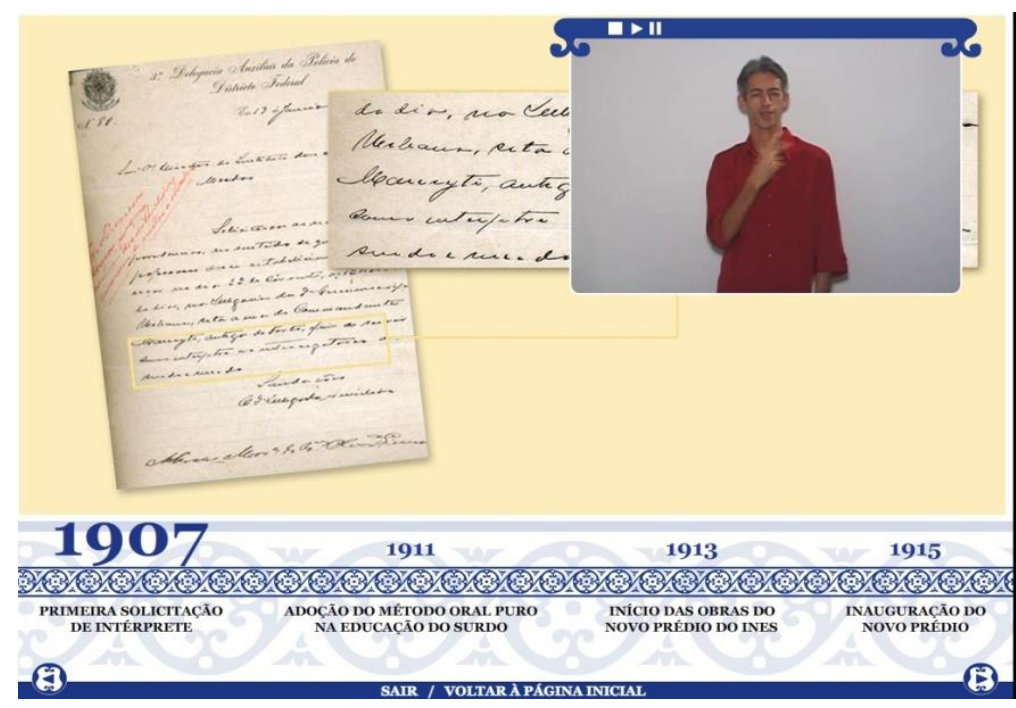

A partir das informações em Libras na tela a direita acima da figura sabemos que essa solicitação formal era para atuar no auxílio nos interrogatórios e depoimentos à polícia. Outro registro histórico da atuação de intérpretes de Libras-Português no contexto jurídico encontrase no artigo 192 do Código de Processo Penal (Decreto-Lei 3689 de 3 de outubro de 1941, cuja redação foi alterada pela Lei $n^{\circ} 10.792$, de 01/12/2003), que preconiza o interrogatório do mudo, do surdo ou do surdo-mudo. É interessante observar que este artigo coloca o intérprete de Libras-Português como necessário somente no caso em que a pessoa surda não saiba ler ou escrever, como vemos no parágrafo único do artigo: "Caso o interrogando não saiba ler ou escrever, intervirá no ato, como intérprete e sob compromisso, pessoa habilitada a entendê-lo" (Brasil, 1941).

Diante do exposto, observa-se que a compreensão do Judiciário brasileiro sobre a língua de sinais ou mesmo sobre os profissionais da interpretação precisa ser revisada. De acordo com Fonseca (2007, p. 1), "Embora a Língua Brasileira de Sinais - LIBRAS - tenha se tornado oficial, no Brasil, por força da Lei 10.436/02, o Judiciário ainda não se apercebeu da necessidade de se adaptar, como preconiza a Convenção Internacional sobre os Direitos das Pessoas com Deficiência, no seu art. 13".

Fonseca (2007), desembargador do Tribunal Regional do Trabalho da $9^{\text {a }}$ Região no estado do Paraná, tem promovido amplo debate sobre a necessidade de "aparelhamento do Judiciário, por meio de intérpretes oficiais de Libras". Tal demanda é oriunda de casos concretos enfrentados pelos juízes que, ao se defrontarem com processos cujos impetrantes sejam pessoas surdas, em certos casos optam por suspender o processo até que seja nomeado 
intérprete de Libras-Português. Fonseca (2007, p. 10) conclui ressaltando a importância do intérprete e alerta que esse profissional deve ter "inclusive noções de termos técnicosjurídicos para que o Juiz possa se comunicar adequadamente e dar a Jurisdição plena e hábil a ser compreendida pelo cidadão surdo".

Todas essas questões apontadas até aqui culminaram na criação de uma comissão de Libras no ano de 2007 pelo Colégio de Presidentes e Corregedores dos Tribunais Regionais do Trabalho - COLEPRECOR constituída por juízes, procuradores, advogados, representantes da FENEIS e uma intérprete de Libras-Português, cuja responsabilidade era a elaboração de um projeto sobre a adoção de intérprete de Libras no âmbito da Justiça do Trabalho. O produto final dessa comissão foi a recomendação $\mathrm{n}^{\circ} 27$ de 16 de dezembro de 2009 aos Tribunais, que trata sobre adoção de medidas para a remoção de barreiras físicas, arquitetônicas, de comunicação e atitudinais a fim de promover o amplo e irrestrito acesso de pessoas com deficiência.

Essas ações foram primordiais para iniciar um debate sobre a presença do intérprete de Libras-Português na esfera jurídica, mas os avanços ainda estão lentos. Conforme Rosa 122 (2011) conclui:

o Sistema Judiciário está pouco preparado para receber tanto a pessoa surda como o intérprete de língua de sinais. Verificou[-se] que normalmente o ILS [intérprete de língua de sinais] é chamado para a segunda audiência devido ao fato de se desconhecer a especificidade linguística da pessoa surda usuária da língua de sinais. (Rosa, 2011, p. 1)

Se por um lado o Judiciário brasileiro não está preparado para atender as demandas da língua de sinais, dentre elas, a interpretação e a tradução, por outro lado há carência na formação dos intérpretes de Libras-Português na esfera jurídica. A atual realidade brasileira conta com pouquíssimos intérpretes de Libras-Português especialistas em determinadas áreas, sendo a formação específica na esfera jurídica uma das mais raras. Rodrigues (2010) investigou os desafios da formação de intérpretes de Libras-Português e questiona-se:

\footnotetext{
Um único ILS [intérprete de língua de sinais] reuniria conhecimentos, habilidades e estratégias para atuar em distintas esferas (internacional e intra-social) e com tipos específicos de interpretação, tais como a interpretação comunitária (communityinterpreting), a interpretação em tribunais (court/legal interpreting), a interpretação médica (healthcare/medical interpreting), a interpretação de diálogo (dialogue interpreting), a interpretação na mídia (media interpreting), a interpretação de ligação ou acompanhamento (liaison/escortinterpreting) e a interpretação de conferência (conferenceinterpreting)? (RODRIGUES, 2010, p.2)
} 
Os contextos de atuação elencados por Rodrigues (2010) estão frequentemente atrelados às rotinas de atuação dos intérpretes de Libras-Português. Em uma tentativa de minimizar a falta de familiaridade desses profissionais e introduzir noções básicas sobre os diferentes contextos de atuação para esses profissionais, o curso de Bacharelado em LetrasLibras da Universidade Federal de Santa Catarina alterou sua grade curricular. Dentre várias mudanças estão as disciplinas de laboratório de interpretação, cujo objetivo principal é a aplicação teórica e prática de interpretação Português-Libras-Português. Por exemplo, a disciplina de Laboratório de Interpretação III trata, especificamente da interpretação de Libras-Português na esfera jurídica, no intuito de inserir o aluno frente as problemáticas mais comuns encontradas naquele meio. Embora não seja suficiente para a capacitação desse futuro profissional, tal mudança curricular foi um passo inicial importante para visibilizar as demandas específicas dessa esfera.

O mercado de trabalho corrobora a esfera jurídica como um dos campos de atuação profissional dessa categoria. Isso pode ser confirmado pela alta demanda por serviços nesse contexto nas Centrais de Intérpretes de Língua de Sinais que estão cada vez mais sendo implementadas em nosso país. Essas Centrais são espaços criados pelo governo, oriundas do Plano Viver sem Limites (Decreto No 7.612, de 17 de novembro de 2011). Nesses espaços é oferecido aos usuários da Língua Brasileira de Sinais, na maioria surdos, o serviço de interpretação de Libras-Português-Libras. Um dos principais objetivos é possibilitar o acesso do cidadão surdo aos diversos setores do serviço público (contexto médico, contexto jurídico dentre outros).

Considerando que a formação específica na área jurídica para os profissionais da interpretação de Libras-Português ainda não foi suprida por um desenho curricular efetivo, cabe-nos investigar quais são as principais dificuldades e desafios que eles enfrentam nesse meio. Esse passo pode trazer elementos que contribuam com o aprofundamento do debate nessa esfera.

\section{Procedimentos metodológicos}

O interesse de compreender melhor alguns temas que atravessam as práticas de intérpretes de Libras-Português que trabalham na esfera jurídica suscitou esta pesquisa. Primeiramente, adotou-se a abordagem qualitativa por compreender que as contribuições desta permitiriam adentrar nos desafios e dificuldades enfrentados pelos intérpretes de LibrasPortuguês na esfera jurídica. Ou seja, conhecer melhor o cenário em que estão imersos, 
descrever alguns dos dilemas pelo viés deles pode contribuir no desenho de uma formação específica para esses profissionais.

Em um segundo momento utilizou-se como técnica de coleta de dados um questionário ${ }^{\mathrm{ii}}$ inserido na plataforma on-line do Google e divulgado aos intérpretes de LibrasPortuguês de todas as regiões do Brasil. A amostragem dessa pesquisa foi ampla, justamente por não termos idéia se teríamos um percentual mínimo de participantes. Entre os principais fatores que justificam a escolha do uso de questionário on-line, destaca-se a facilidade de atingir um número maior de intérpretes.

O questionário continha perguntas de múltipla escolha e uma pergunta aberta sobre as dificuldades enfrentadas pelos profissionais. O intuito dessa pergunta era recolher uma quantidade maior de informações de acordo com as experiências dos intérpretes na esfera jurídica. O questionário on-line foi disponibilizado entre os meses de julho e agosto de 2014, totalizando 39 participantes. Os resultados serão discutidos e analisados à luz de uma pergunta central deste trabalho: quais são as dificuldades e os desafios com que os intérpretes de Libras-Português que atuam na esfera jurídica lidam em seus cotidianos?

\section{Dificuldades e desafios}

Neste tópico apresento a discussão dos resultados coletados na pesquisa. Para discutir as dificuldades e os desafios que os intérpretes de Libras-Português enfrentam na esfera jurídica é preciso compreender como esses profissionais são solicitados ou se dirigem até o Judiciário, o que frequentemente ocorre de maneira informaliii, o que pode ser um dos primeiros obstáculos enfrentados nessa esfera. Os participantes da pesquisa, em sua maioria, afirmam ter sido localizados para esse tipo de atuação a partir de diferentes meios e espaços, conforme mostra a tabela abaixo.

Tabela 1 - Diferentes formas como os intérpretes chegam até o Judiciário

\begin{tabular}{|l|l|}
\hline \multicolumn{1}{|c|}{ Tipos de acesso dos intérpretes de Libras-Português ao Judiciário } & \multicolumn{1}{|c|}{ Porcentagem } \\
\hline Amizade com o cliente surdo & $22 \%$ \\
\hline Central de intérpretes & $3 \%$ \\
\hline Associações de Tradutores e Intérpretes de Libras-Português & $3 \%$ \\
\hline Associações de Surdos & $19 \%$ \\
\hline Outros & $53 \%$ \\
\hline
\end{tabular}

Fonte: Própria da autora 
Os resultados apresentados acima denunciam uma realidade preocupante para a área da língua de sinais em nosso país, haja vista que a categoria "outros" totaliza mais da metade dos encaminhamentos dos serviços de interpretação de Libras-Português ao Judiciário. Nessa categoria foram registradas diversas formas desses encaminhamentos: por meio de indicações de colegas, escola, empresa, pastoral de surdos, universidades ou ainda secretaria de assistência social. Logo em seguida, constata-se que muitos dos intérpretes de LibrasPortuguês são encaminhados até o Judiciário por intermédio da amizade com pessoas surdas, o que pode influenciar de forma desfavorável nas relações de atuação profissional e na profissionalização nesse meio.

Esse resultado alerta para o fato de que as centrais de intérpretes de língua de sinais ou as associações de tradutores ou intérpretes representam percentual pouco expressivo no encaminhamento dos serviços de interpretação de Libras-Português para a esfera jurídica. Tal fato denota a necessidade de refletirmos sobre a regulamentação e a implementação de processos para encaminhar os serviços de interpretação de língua de sinais ao Judiciário. Dito de outra forma, se esse encaminhamento encontra-se fragilizado por falta de institucionalização, tal fato precisa ser revisado tanto pelas instâncias governamentais quanto pelos profissionais da área.

Nessa perspectiva, não é aceitável que a atuação do intérprete de Libras-Português seja entendida somente no ato propriamente dito da interpretação das línguas envolvidas em determinado caso. Como em qualquer outra esfera, a atuação desse profissional no âmbito jurídico está diretamente relacionada com etapas que envolvem o "antes, durante e depois" da prestação dos serviços. Por exemplo, a preparação de intérpretes é uma etapa fundamental para a atuação desses profissionais, assim como a etapa final, que poderia prever a avaliação dos serviços prestados.

Em relação à preparação prévia, os resultados desta pesquisa constataram que $45 \%$ dos participantes relataram não encontrar com facilidade materiais que auxiliem nessa etapa e $18 \%$ preferem solicitar informações diretamente ao profissional da área jurídica ou mesmo à pessoa surda. Os participantes ressaltam ainda que são raras as publicações sobre o tema no Brasil. Outros tópicos mencionados são a demora na realização da pesquisa, mesmo quando existem materiais, citada por $6 \%$ dos participantes. Apenas $9 \%$ afirmaram encontrar materiais com certa facilidade.

De forma geral, o que se observa é que os intérpretes de Libras-Português que atuam na esfera jurídica ressaltam que uma das maiores dificuldades desse contexto é a complexa 
terminologia empregada nos discursos. De fato, esse é um tema que nos convoca a desenvolver pesquisas e ações conjuntas em torno da criação de glossários, manusear ferramentas que disponham de banco de dados com sinais catalogados, dentre outros pontos. Nesse quesito, uma das iniciativas que têm contribuído para ampliar a terminologia da área jurídica em Libras é a proposta de criação de um glossário jurídico em Libras.

Este projeto, de autoria do desembargador Ricardo Tadeu Marques da Fonseca juntamente com alunos surdos do curso de Direito e especialistas da área de língua de sinais de diferentes instituições, buscou reunir um Grupo de Trabalho responsável pela criação do Glossário Jurídico em Libras. No entanto, o desembargador, em um vídeo ${ }^{\mathrm{iv}}$ publicado em 27 de outubro de 2015, adverte a comunidade surda sobre a falta de engajamento desse público frente aos trabalhos propostos. Além disso, menciona uma série de argumentos e implicações decorrentes da falta desse tipo de trabalho. Por fim, declara a suspensão dos trabalhos até que um posicionamento mais engajado por parte da comunidade surda seja visível ao Tribunal.

As pesquisas sobre terminologia e língua de sinais na esfera jurídica são recentes, tais como Vale (2015), que tratou sobre "o juridiquês e o processo de tradução-interpretação para 126 a língua de sinais". Nesse trabalho, a autora explora uma série de discussões que envolvem a tradução da linguagem jurídica e as implicações desta para a língua de sinais. Todas essas ações em torno da terminologia na esfera jurídica contribuem fundamentalmente na atuação profissional do intérprete de Libras-Português nesse meio, ainda que Russel (2002) elenque outros elementos que interessam a essa categoria.

Russel (2002) realizou diversas entrevistas pós-julgamento com intérpretes, peritos, testemunhas surdas, juízes e advogados. Com relação aos intérpretes cinco tópicos importantes foram detectados: preparação (conteúdo, necessidades do intérprete, estratégias eficazes); interpretação (consecutiva, simultânea, divisão das mensagens em blocos); discurso de tribunal (ritmo/complexidade, nervosismo, impacto do estilo do discurso); processos de formação de equipe (trabalho em equipe e confiança nos colegas); anotações (estratégias e materiais preparados). Essas entrevistas realizadas por Russel (2002) contribuem com elementos importantes para a realidade brasileira, pois tais tópicos e subtópicos podem ser discutidos com todos os participantes que atuam na esfera jurídica a fim de institucionalizar o papel e a função do intérprete de Libras-Português naquele meio.

Em nossa pesquisa, os participantes mencionaram dificuldades como: desconhecimento do papel do intérprete pelo Judiciário, tempo de duração das seções, o fato de trabalhar sozinho, a dificuldade de acesso a material prévio, a falta de previsão legal 
(orientações, normativas) sobre a atuação do intérprete de Libras-Português nesse meio, ausência de competência referencial, dentre outros.

Alguns dessas dificuldades, entre outras, também foram constatadas em outros pares lingüísticos. Nordin (2013), por exemplo, apresenta vários desafios enfrentados na interpretação inglês-português na esfera jurídica, como: rapidez na fala do advogado, conflito de interesses, interação com os assistentes judiciários, terminologia técnica, atuação cultural ou linguística dentre outros. Ou seja, a abordagem desses pontos é necessária na formação do intérprete que atua na esfera jurídica, independente do par linguístico no qual ele trabalha. Além disso, a fim de qualificar os serviços oferecidos e suscitar pesquisas nesse campo, constata-se a necessidade de padronizar os serviços de interpretação de Libras-Português oferecidos na esfera jurídica.

\section{Considerações finais}

Este artigo buscou discutir algumas dificuldades e desafios que permeiam o campo da interpretação de Libras-Português na esfera jurídica em nosso país. Em um primeiro momento, mostrou-se que no contexto internacional há estudos sobre a interpretação na esfera jurídica, isto é, temos o campo melhor sedimentado. Essa realidade internacional é um pouco distante do contexto brasileiro. Ilustramos algumas iniciativas que marcaram a história da interpretação de Libras-Português, mas observamos que o campo ainda é incipiente de pesquisas tanto no nível teórico quanto no aplicado. Tomando como princípio a abordagem qualitativa, exploraram-se os dados coletados de um questionário aplicado a 39 intérpretes de Libras-Português de diferentes regiões brasileiras.

Uma das dificuldades que teve destaque foi a falta de institucionalização no encaminhamento de intérpretes de Libras-Português até o Judiciário, pois relações pautadas na amizade ou no conhecimento do cliente contribuem para que os intérpretes sejam conduzidos a diferentes setores da esfera jurídica. Outro tópico constatado foi a falta de termos jurídicos traduzidos para a Libras. Nesse sentido, mostrou-se uma iniciativa com o objetivo de criar um glossário de termos jurídicos, que contava com a participação de especialistas surdos e ouvintes, intérpretes de Libras-Português, um desembargador e estudantes de Direito.

A partir dos dados analisados faz-se necessário apontar alguns desafios para a atuação dos intérpretes de Libras-Português na esfera jurídica, dentre eles: a necessidade de formação específica para atuação nesse meio, de investimento em pesquisas e formação de recursos 
humanos na área da interpretação de Libras-Português, de aquisição de literatura clássica da área, entre outros. A formação por competências na interpretação de Libras-Português para atuar na esfera jurídica é um dos grandes desafios a ser enfrentado. Em alguns casos, como menciona a lei $\mathrm{n}^{\mathrm{o}} 12.319$ de 1 de setembro de 2010 em seu artigo 6º a compreensão equivocada que se tem sobre as atribuições do intérprete de Libras-Português é de que esse profissional estaria apto a exercer seu papel em diferentes contextos, isto é, da esfera educacional à esfera jurídica.

Por fim, sugere-se que novas pesquisas sejam realizadas sobre os serviços de interpretação de Libras-Português na esfera jurídica, especialmente aquelas que investiguem as competências específicas e o papel do intérprete nesse meio, as formas de preparo da interpretação, questões de ética e comportamento, a implementação e a qualidade do trabalho prestado.

\section{REFERÊNCIAS BIBLIOGRÁFICAS}

BRASIL. Lei $n^{\circ} 10.436$, de 24 de abril de 2002. Dispõe sobre a Língua Brasileira de Sinais 128 Libras e dá outras providências. Diário Oficial da União, República Federativa do Brasil, Atos do Poder Legislativo, Brasília, DF, 25 abr. 2002. № 79, ano CXXXIX, Seção 1, p. 23.

Lei $\mathrm{n}^{\circ} 12.319$, de 01 de setembro de 2010. Dispõe sobre a regulamentação da profissão de Tradutor e Intérprete da Língua Brasileira de Sinais - Libras. Diário Oficial da União, República Federativa do Brasil, Atos do Poder Legislativo, Brasília, DF, 2 set. 2010. No 169, ano CXXXIX, Seção 1, p. 43.

. Decreto-Lei 3689, de 3 de outubro de 1941. Dispõe sobre o Código de Processo Penal. Diário Oficial da União, República Federativa do Brasil, Atos do Poder Legislativo, Brasília, DF, 13 out. 1941. Ano CXXXIX, Seção 1, p.19699

. Decreto $\mathrm{N}^{\mathrm{o}}$ 7.612, de 17 de novembro de 2011. Dispõe sobre o Plano Nacional da Pessoa com Deficiência - Plano Viver sem Limite. Diário Oficial da União, República Federativa do Brasil, Atos do Poder Legislativo, Brasília, DF, 18 nov.2011. Ano CXXXIX, Seção 1, p.12.

EDWARDS, Alicia B. The practice of court interpreting. John Benjamins Publishing, 1995.

FONSECA, Ricardo T. M. Libras no Judiciário: um débito social. In: Revista LTr. Legislação do Trabalho, v. 71-II, p. 1068-1071, 2007. Disponível em: http://www.inclusive.org.br/?p=13321. Acesso em: 15 fev.2016.

GONZÁLEZ, Roseann D.; VÂSQUEZ, V.; MIKKELSON, Holly. Fundamentals of Court Interpretation: Theory. Policy and Practice. Durham, NC: Carolina Academic Press, $2^{\mathrm{a}}$ edição, 2012. 
MATHERS, Carla M. Sign language interpreters in court: Understanding best practices. AuthorHouse, 2006.

NORDIN, Jaqueline. Interpretação Forense: ética e padronização profissional, São Paulo, 1edição, 2013.

ROCHA, Solange. O INES e a educação de surdos no Brasil: aspectos da trajetória do Instituto Nacional de Educação de Surdos em seu percurso de 150 anos. Revista Espaço, Rio de Janeiro, 2008.

RODRIGUES, Carlos H. Da interpretação comunitária à interpretação de conferência: Desafios para formação de intérpretes de língua de sinais. In: II Congresso Nacional de Pesquisa em Tradução e Interpretação de Língua de Sinais Brasileira, Universidade Federal de Santa Catarina, Florianópolis, 2010.

ROSA, Andréa da. S.A contribuição da universidade para um sistema judiciário inclusivo: o intérprete de língua de sinais nos depoimentos de surdos no Tribunal da Justiça. Apresentação realizada no Congresso dos Profissionais das Universidades Estaduais de São Paulo, outubro de 2011. Material disponível em: http://sistemas.rei.unicamp.br/ggbs/conpuesp/posteres/201192811409.pdf

RUSSELL, Debra L. Interpreting in legal contexts: Consecutive and simultaneous interpretation. Burtonsville, MD: Linstock Press, 2002, 256p.

VALE, Luciana M. O juridiquês e o processo de tradução-interpretação para a língua de sinais. In: VI Congresso Internacional de Tradução e Interpretação da ABRATES, 2015. São Paulo, 2015.

iSilvana Aguiar dos SANTOS -Professora Adjunta no curso de Letras-Libras da Universidade Federal de Santa Catarina. Doutora em Estudos da Tradução pela Universidade Federal de Santa Catarina (2013). Mestre em Educação pela Universidade Federal de Santa Catarina (2006). Graduação em Educação Especial pela Universidade Federal de Santa Maria (2001). Disponível em: http://lattes.cnpq.br/2132093144348796. Acesso: junho de 2016.

ii Este questionário intitulado "Interpretação de língua de sinais/língua portuguesa e seus múltiplos contextos" foi elaborado a fim de coletar dados da palestra "A atuação de intérpretes de Libras-Português: novos desafios em diferentes contextos", pertencente à programação do $8^{\circ}$ Encontro Nacional dos Estudantes de Letras Libras ENELL ocorrido de 29 de setembro a 3 de outubro de 2014. O questionário foi composto de perguntas que exploravam cinco contextos de atuação (educacional, religioso, conferência, médico e jurídico). Neste artigo, analiso somente os dados referentes à esfera jurídica. Agradeço a participação das alunas Aline Poltronieri Gessner e Walquíria Peres Amorim.

iii Em determinados casos, o encaminhamento formal de um intérprete de Libras-Português pode estar atrelado aos próprios órgãos da esfera jurídica ou policial, como a Delegacia da Pessoa com Deficiência (Secretaria das Pessoas com Deficiência do estado de São Paulo). Em outras situações, os intérpretes de Libras-Português podem ser convocados mediante documentos oficiais do Judiciário.

iv Este vídeo pode ser visualizado no endereço: https://www.youtube.com/watch?v=2bftKVrk-us

RECEBIDO EM: 09 de março de 2016 ACEITO EM: 15 de abril de 2016 